$$
\begin{aligned}
& \text { ريختشناسى Fرده كونه هاى سرده . Rubus L، زيرسرده Rubus در اير ان }
\end{aligned}
$$

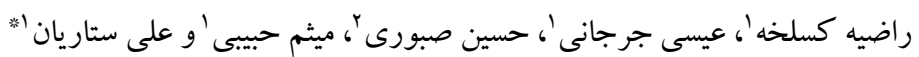

$$
\begin{aligned}
& \text { دريافت: } \\
& \text { اخرُوه زيستشناسى، دانشكدة علوم، دانشگاه كُبد كاووس، گنبد كاووس، اير ان }
\end{aligned}
$$

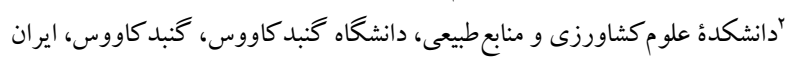

$$
\begin{aligned}
& \text { مattarian@gonbad.ac.ir مسئول مكاتبات }
\end{aligned}
$$

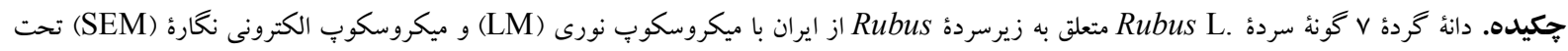

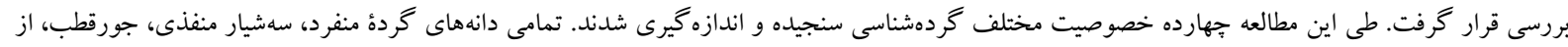

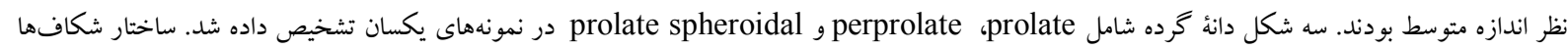

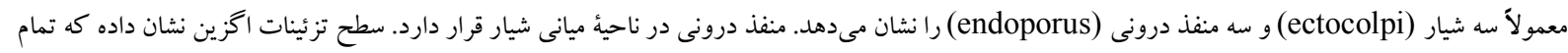

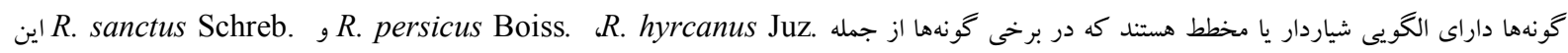

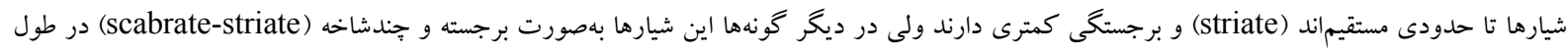

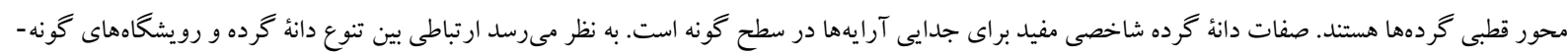
ها نيز وجود دارد. وازههاى كليدى. اخزين، سه شياره، دانه گرده، طرح اثر انخشت، محور قطبى، ميكروسكوبٍ الكترونى

\title{
Pollen morphology of the genus Rubus L. subgenus Rubus (Rosaceae) in Iran Razieh Kasalkheh ${ }^{1}$, Eisa Jorjani ${ }^{1}$, Hossein Sabouri ${ }^{2}$, Meisam Habibi ${ }^{1} \&$ Ali Sattarian ${ }^{2 *}$
} Received 23.04.2016/ Accepted 19.12.2016/ Published 21.06.2017

${ }^{1}$ Department of Biology, Faculty of Science, University of Gonbad-e- Kavous, Gonbad-e- Kavous, Iran ${ }^{2}$ Department of Plant Production, Faculty of Agricultural and Natural Resources, University of Gonbad-e- Kavous, Gonbad-e- Kavous, Iran

${ }^{*}$ Correspondent author: sattarian@gonbad.ac.ir

Abstract. Pollen grains of 7 species of the genus Rubus L. were investigated using light microscopy (LM) and scanning electron microscopy (SEM). 14 different pollen characters were described, illustrated and compared in the present study. All pollen grains were monad, tricolporate, radially symmetrical, isopolar, and medium in size. As for pollen shape, 3 forms were recognized in the same specimens: prolate, perprolate and prolate-spheroidal. Endopore was located in the middle of colpi. The sculpture of the grains was confirmed to have striate pattern. The size of perforation and the orientation of the muri were compared and appeared to indicate the differences between the species. R.caesius, $R$. discolor, $R$. dolichocarpus and $R$. hirtus appear to have steriate-scabrate sculpture; in contrast, $R$. hyrcanus Juz., $R$. persicus Boiss. and $R$. sanctus Schreber. appear to have meandrical and fingerprint-like sculpture. Perforations are of two types. They are either large or often extending to tectal ridges or minute holes. Characters of pollen grains were proved their usefulness for separating taxa at the specific level. It seems that there is a link between the diversity of pollens and the vegetation habitats.

Keywords. exine, ectocolpi, pollen, finger prints pattern, polar axis, electron microscopy

(1911, 1914; Hummer, 1996

يا علفى جندساله با ساقههاى خاردار هستند كه معمولاً شاخهُ گل -

دهنده روى ساقه هاى بلند جوبى سالهاى قبل بلهوجود مى آيد.

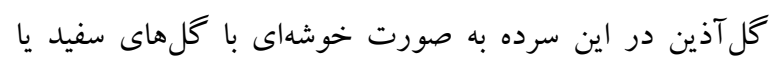

صورتى و ميوه مجتمع جندبرجهاى هستند (19hatamsaz,

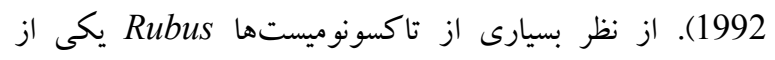

مقدمه

Rosaceae يكى از اعضاى تمشك تمه Rubus L. سهو Rosoideae است كه به زيرتيره كلسرخيان Juss. دارد.كونههاى اين سرده براكنش وسيعى دارند طورى كه در تمام قارهها، از مناطق استو ايى بـت تا نواحى نيمهقطبى ( Thompson, 1995) بهجز ناحيةٌ قطب جنوب، يراكنش دارند ( Focke, 1910, 
1978). مطالعهُ دانهُ گرده در گلسرخيان تاريخجهاى طولانى دارد (Tomlik-Wyremblewska, 1995). مقادير زيادى شهد توليد مى كنند كه حشرهها را به سمت خود جلب مى كنند. بنابراين، گردهافشانى در اين سرده عموماً به وسيلة حشرهها انجام مى شود (Jenning, 1988).

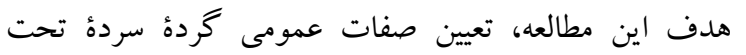

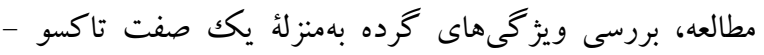

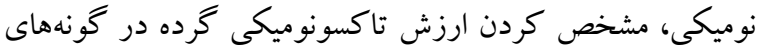

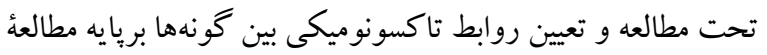
صفات دانه گرده زيرسرده Rubus در ايران با مشاهدات ميكروسكوبٍ نورى (LM) و ميكروسكوبٍ الكترونى (SEM)

\section{مواد و روشها}

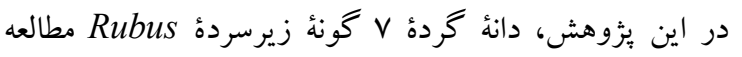
شدند. نمونهها بهطور مستقيم از رويشگاههاى طبيعى سه استان

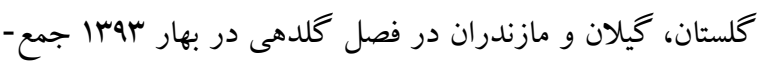

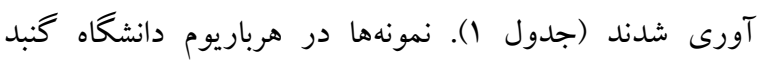

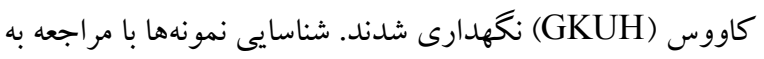

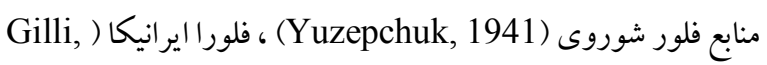

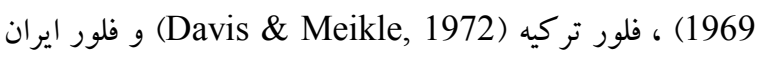
(Khatamsaz, 1992)

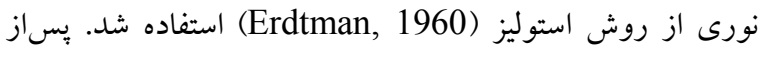

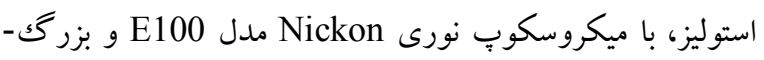

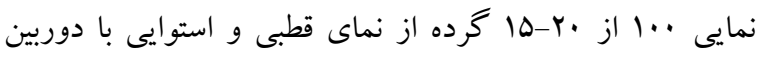

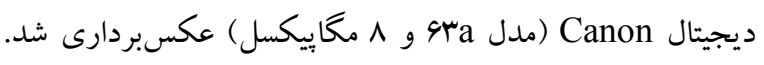

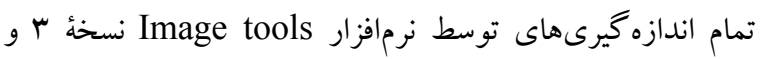
Axio vision

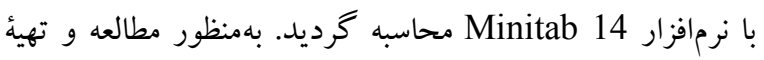
ميكرو گرافهاى الكترونى، دانهاى گردهُ مناسب با استفاده از

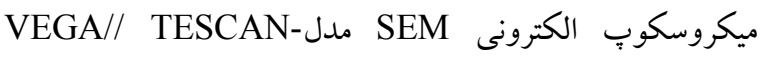
22KV, 15 KV تررسى و تصويربردارى مدل ولتاز LMU

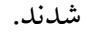

Tomlik-Wyremblewska, براى اصطلاحات دانه گرده از

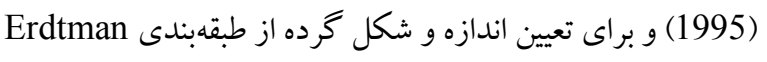

برجالشترين گياهان كلدار است (Richard et al.,1996). آمار دقيقى براى تعداد گونهاى اين سرده وجود ندارد. تنها طبقهبندى جهانى و جامع، به كوشش (1910, 1911, 1914) Focke انجام كرفته است Focke .Thompson, 1997) در اين طبقهبندى،

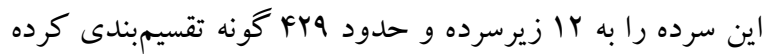

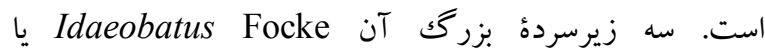

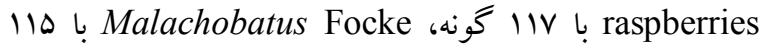
كونه و Rubus=EubatusFocke يا با با تقريباً

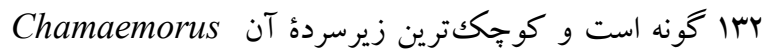

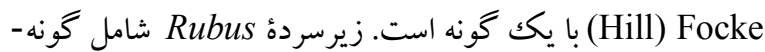
هايى است كه در ارويا، آسيا و آمريكاى شمالى انتشار دارند (Ballington et al., 1993) (كونهاى جوبى موجود در ايران همخى متعلق به زيرسردة Rubus هستند و گونههاى مختلف اين زيرسرده علاوهبر ايران، در ارويا، تركيه، قفقاز، افغانستان، باكستان، عراق و لبنان يافت مىشوند (Khatamsaz, 1992).

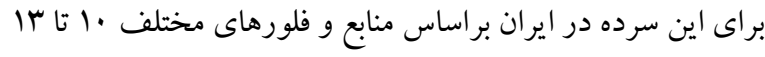
كونه معرفى شده است كه حاكى از اختلاف نظر ميان گياهشناسان

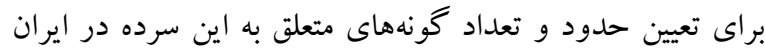

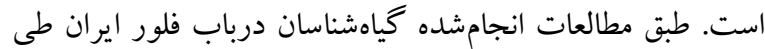
جند قرن اخير، تعداد گونههاى معرفىشده براى اين سرده تا حدى متفاوت بوده است. بهطورى كه Boissier (1872) در فلورا

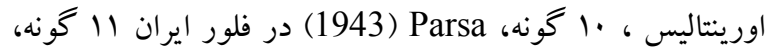
Gilli Khatamsaz

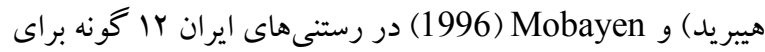

$$
\text { اين سرده از ايران نام بردهاند. }
$$

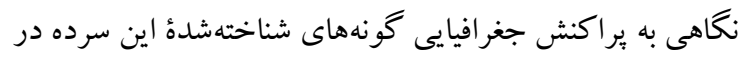
تمام منابع فلورى نشان مىدهد كه در ايران مركز تنوع و بر براكنش

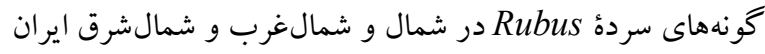

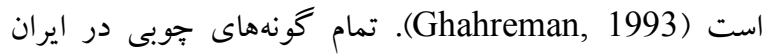

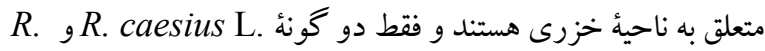
sanctus Schreb.

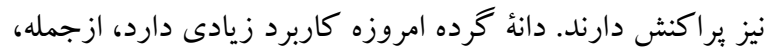

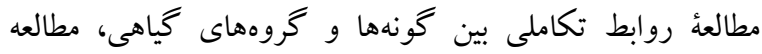

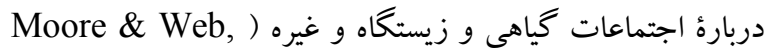


جدول ا- نمونههاى تحت مطالعه كونهاى زيرسردة

Table 1. List of the specimens studied.

\begin{tabular}{|c|c|c|c|c|c|}
\hline شماره هرباريومى & جمع آورى كننده & ارتفاع) & محل جمع آورى & كونه & 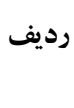 \\
\hline 803012-GKUH & كسلخه و حيبيى & $\Delta \cdot$ & مازندران، رامسر، قاسم آباد سفلى & R. caesius L. & 1 \\
\hline 803026-GKUH & كسلخه و حبيى & $v$ & كَيلان، هشتير، شير آباد & $\begin{array}{l}\text { R. discolor Weihe \& } \\
\text { Nees. }\end{array}$ & $r$ \\
\hline 803120-GKUH & كسلخه و مهدى يانى & $\Delta . \cdot$ & گَلستان، پِارك ملى گلستان & R. dolichocarpus Jaz. & $r$ \\
\hline 803135-GKUH & كسلخه و مهدى يانى & ira. & مازندران، جنكل سنگده & $\begin{array}{l}\text { R. hirtus Waldst \& } \\
\text {.kit }\end{array}$ & $\varepsilon$ \\
\hline 803146-GKUH & كسلخه و حيبى & $1 . r$. & گَيلان، جاده اسالم به خلخال & R. hyrcanus Juz. & 0 \\
\hline 803150-GKUH & مهدى يانى & ro. & كلستان، جنكل امامرضا (ع) كرد كوى & R. persicus Boiss. & 7 \\
\hline 803235-GKUH & كسلخه و حبيب & 1.4. & زيارتخاه، جيرنده، روستاى بىورزين، نزديكى & R. sanctus Schreb. & v \\
\hline
\end{tabular}

شيار: تمام گردههاى تحت مطالعه داراى سه شيار (ectocolpi)

و سه منفذ درونى (endoporus) هستند. شيارها در امتداد محور

قطبى گرده است كه تقريباً •V-•9 درصد محور قطبى را در گونه-

هاى مختلف تشكيل دادهاند. بيشترين و كمترين طول شيار به-

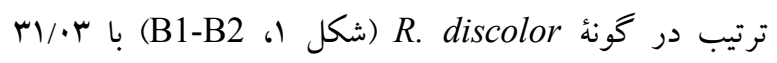

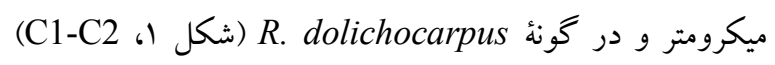
هـ/·r ميكرومتر است. انتهاى شيارها تيز است و در ميانه داراى يل هاى عرضى هستند.

ضخامت اكزين: كل ضخامت اتزين در ميكروكرافهاى

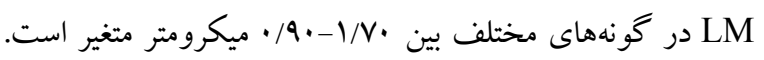

بيشترين ضخامت اكزين در گونهاى A2 caesius

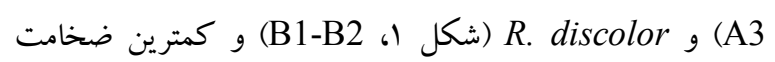
مربوط به گونهاى Rirtus persicus

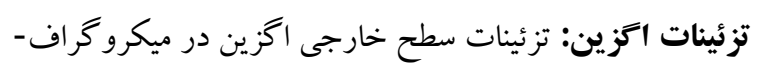
هاى SEM نشان داد كه گونه

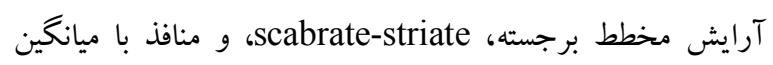

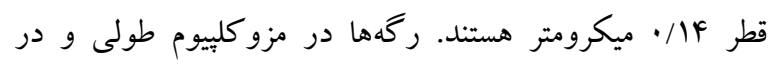

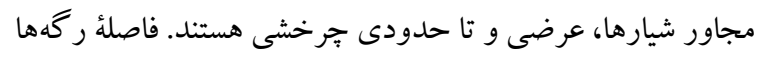

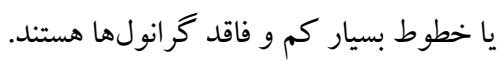

كونه

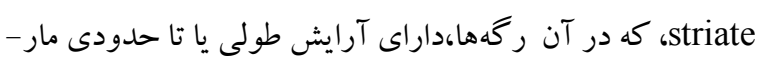

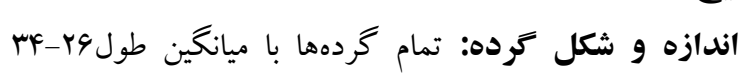

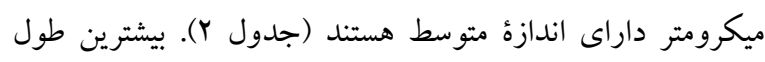

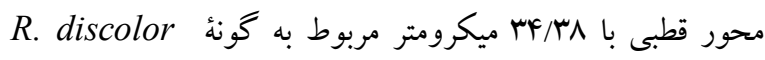
R. Weihe \& Nees. hyrcanus Juz.

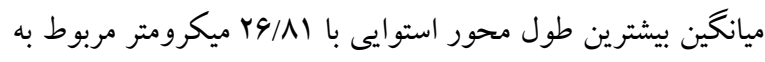

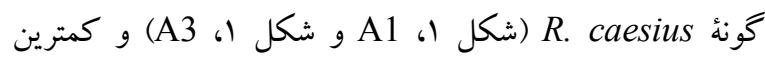

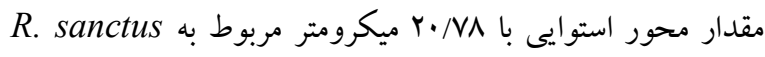
(شكل )، G2) است. ازلحاظ شكل، تمام گردهها منفرد، جور قطب و تقارن شعاعى هستند. ازمنظر قطبى بيضوى شكل و ازمنظر

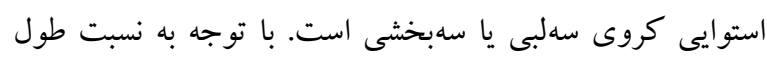

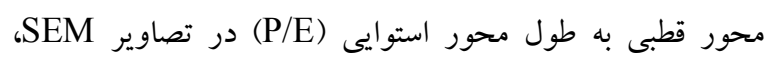

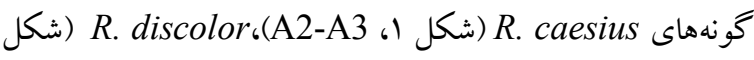

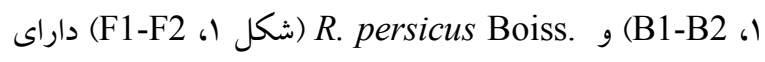

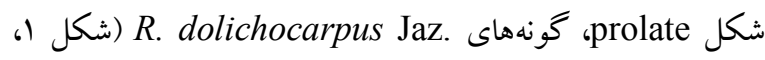
و (A) hirtus Waldst \& Kit. ، (C1-C2 (شكل ) R. Ryrcanus perprolate شكل prolate-spheroidal هستند. 


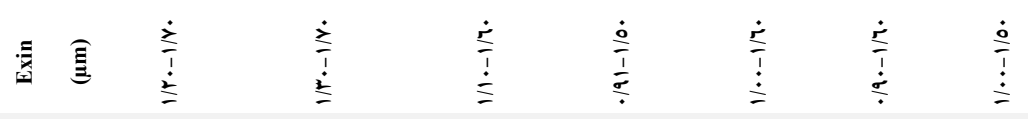
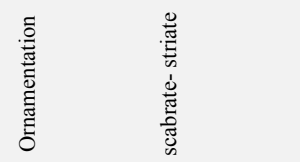

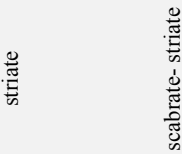

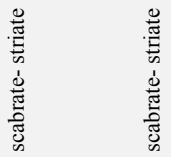

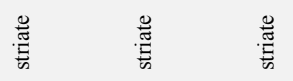

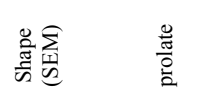

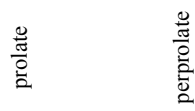

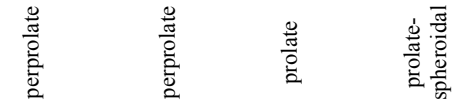

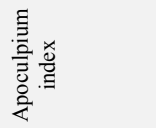

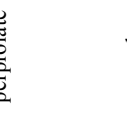

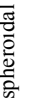

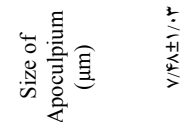

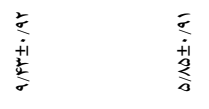

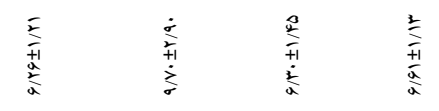

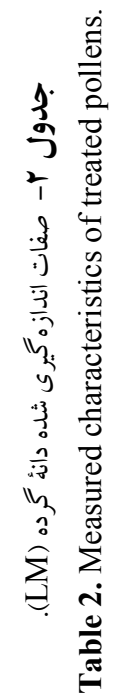

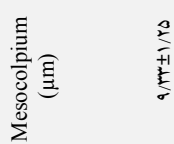

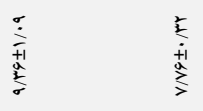

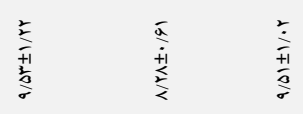
$\underset{\substack{2 \\ \frac{1}{2}}}{\frac{1}{2}}$

害产重竞

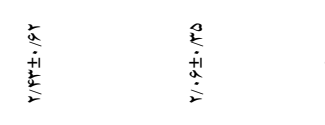

$\frac{2}{2}$

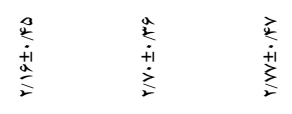

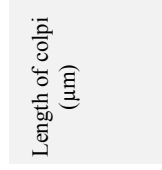

$\frac{\sqrt{2}}{\frac{2}{2}}$

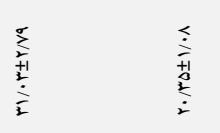

$\frac{\sqrt{2}}{\frac{2}{2}}$

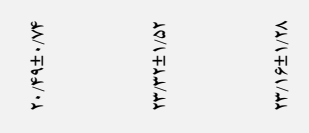

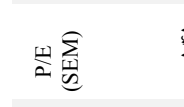

똘

橤四恶

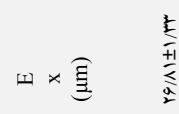

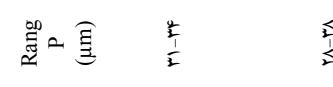

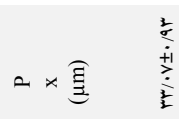

等

$\frac{5}{2}$

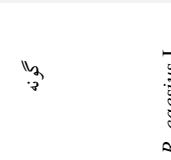

$\frac{2}{2}$

\begin{tabular}{|c|c|c|}
\hline$\frac{1}{2}$ & $\frac{2}{2}$ & 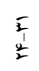 \\
\hline & $\begin{array}{l}\frac{1}{2} \\
\frac{1}{+1} \\
\frac{1}{2} \\
\frac{1}{2}\end{array}$ & $\overline{\bar{a}}$ \\
\hline
\end{tabular}

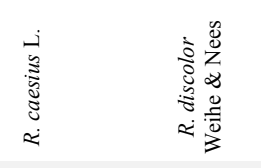

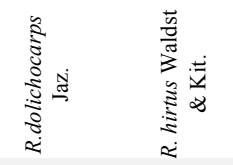

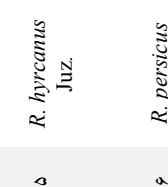




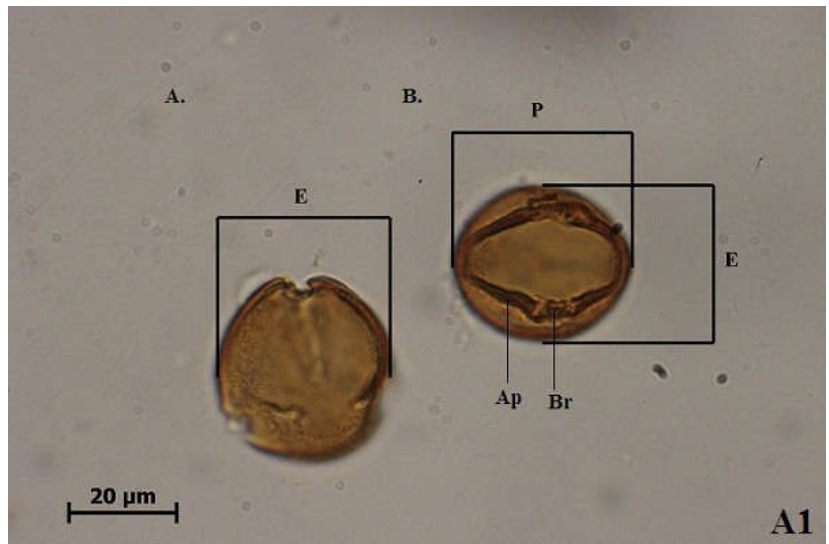

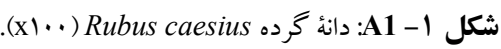

Fig. 1. Pollen of Rubus caesius (x100).

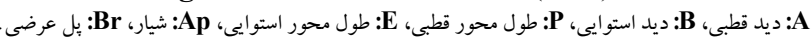

A: polar view, B: equatorial view, P: length of polar axis, E: length of equatorial axis, Ap: aperture, Br: bridge.

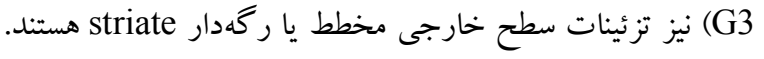

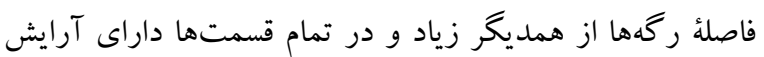

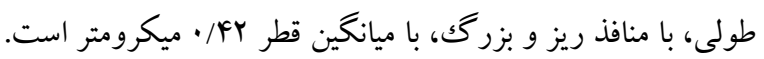

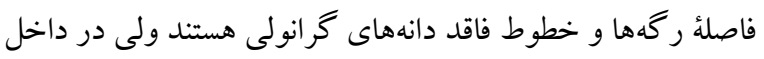

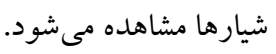

\section{بحث}

تمام دانههاى گردهُ مورد بررسى جورقطب، با تقارن شعاعى و

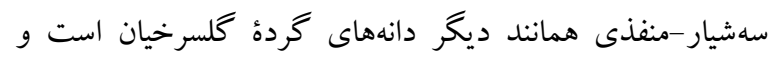

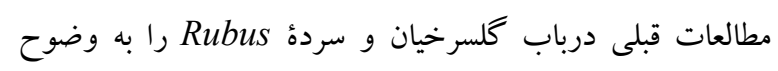

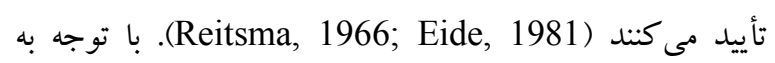

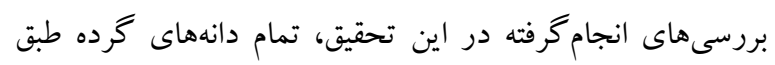

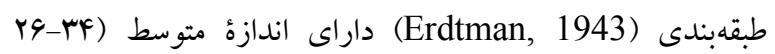

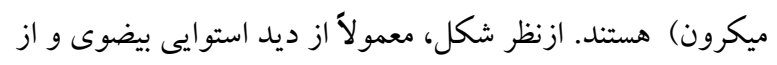

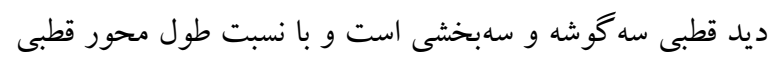

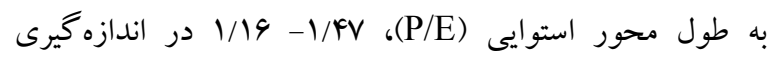

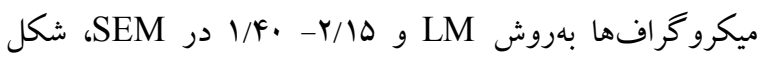

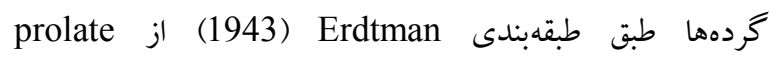

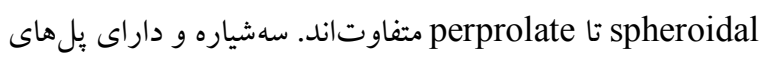
عرضى استو ايى در محل شيارها هستند. ضخامت اكزين در بين

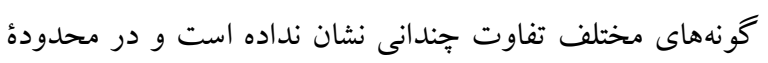

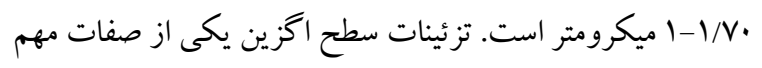

يبيجى در مزو كلييوم هستند، در قسمتهاى انتهايى قطبى بهصورت

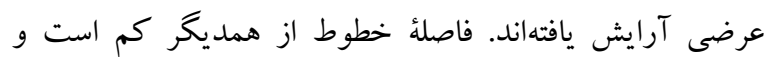

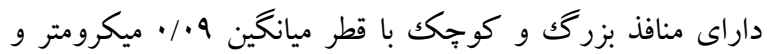
كاهى داراى گرانول بين يا روى خطوط است. R. dolichocarpus مخطط منشعب scabrate-striate هستند. رگهها در تمام قسمت-

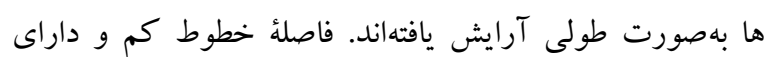
منافذ بسيار ريز با ميانخين قطر 4.

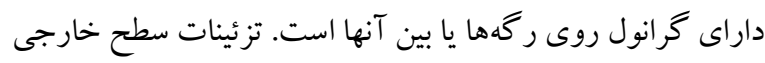

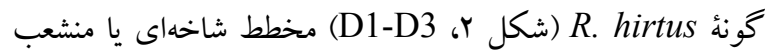
scabrate-striate

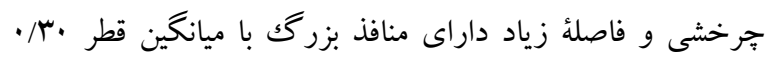
R. ميكرومتر و منافذ كوجگك با ميانگين قطر 9. striate شكل hyrcanus

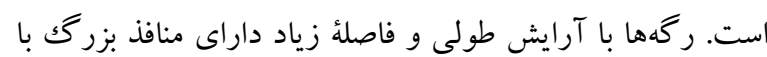

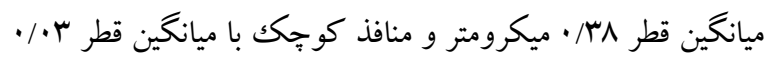
ميكرومتر است و در سطح فاقد گرانول هستند. تزئينات سطح

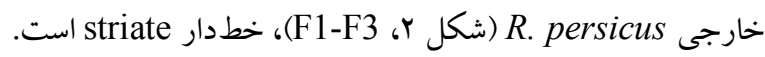

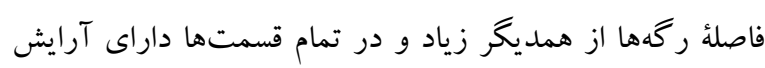

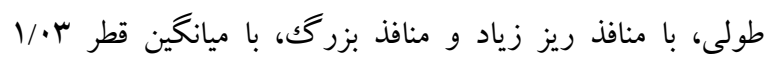

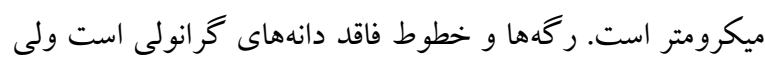

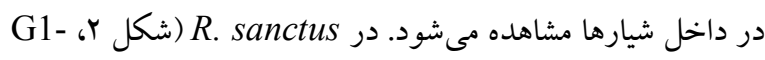




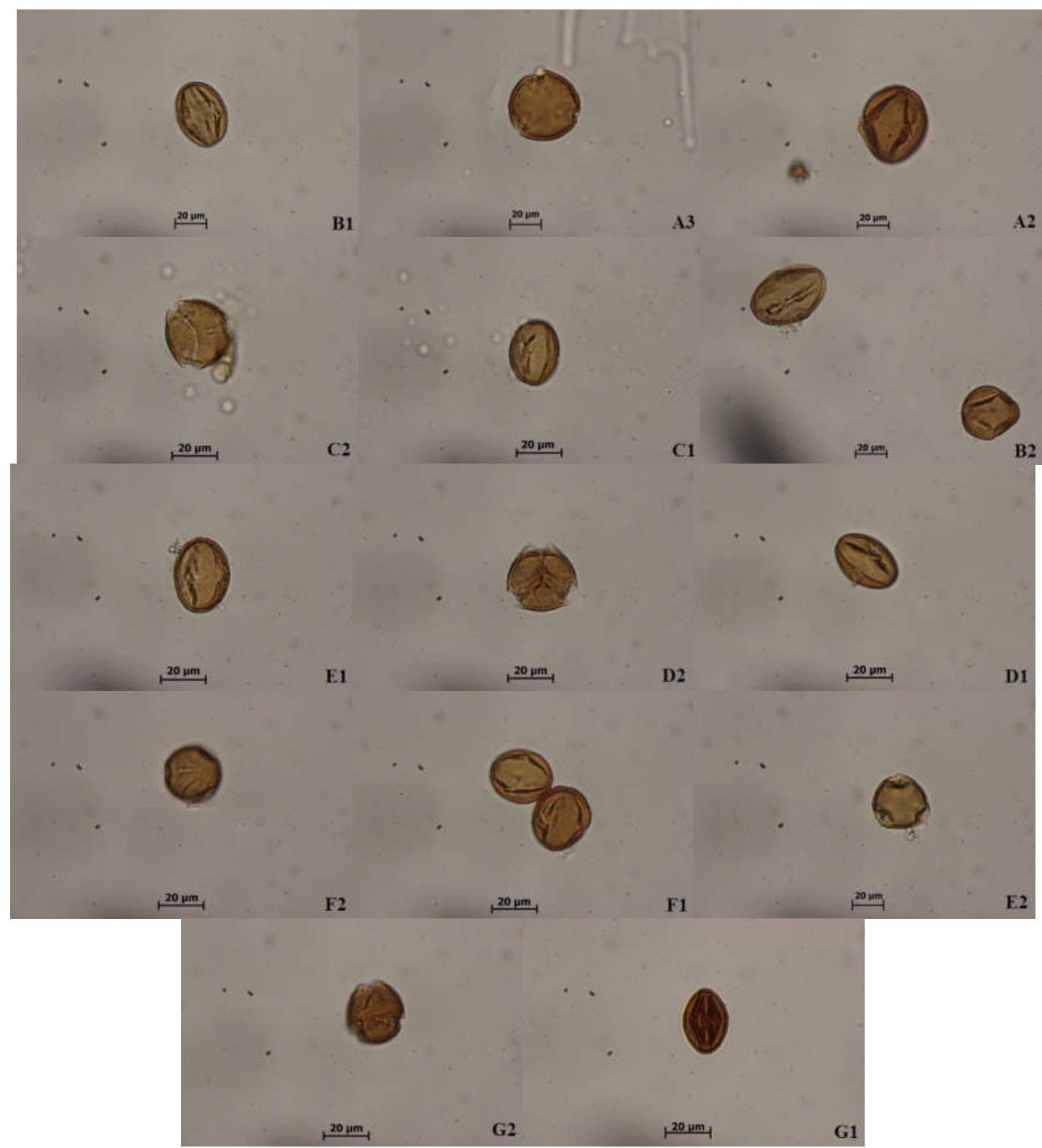

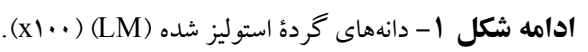

Fig. 1. Acetolyzed pollen grains (LM) (x100).

A2: ديد استوايى، A3: ديد قطبى B2

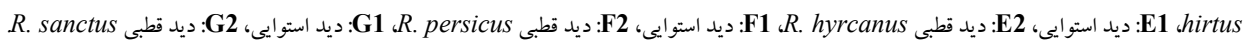

A2: equatorial view, A3: polar view- R.caesius; B1: equatorial view, B2: polar view- $R$. discolor; C1: equatorial view, C2: Polar view- $R$. dolichocarpus; D1: equatorial view, D2: polar view- $R$. hirtus; E1: equatorial view, E2: polar view- $R$. hyrcanus; F1: equatorial view, F2: polar view$R$. persicus; G1: equatorial view, G2: polar view- $R$. sanctus. 


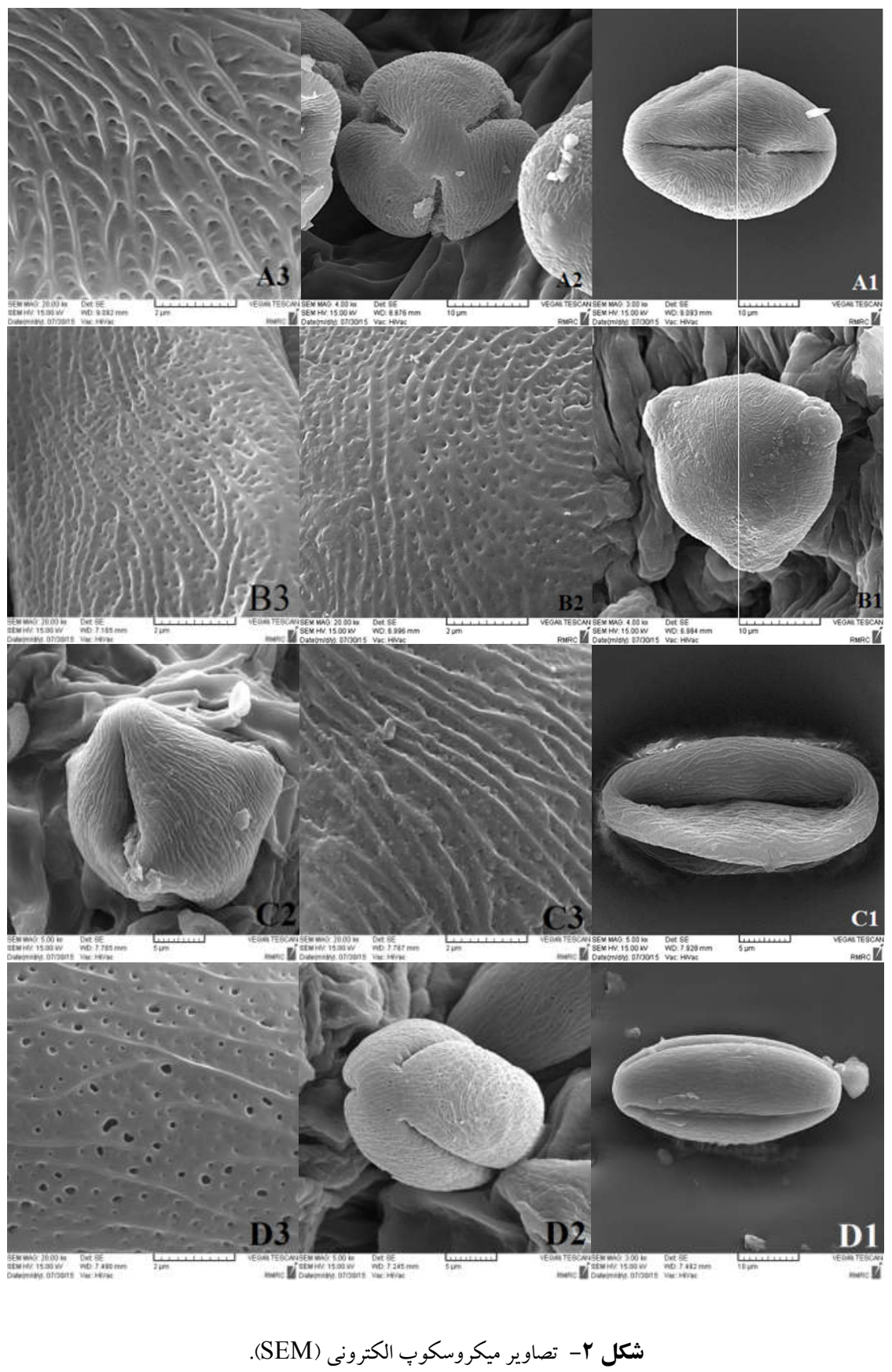

Fig. 2. SEM micrographs.

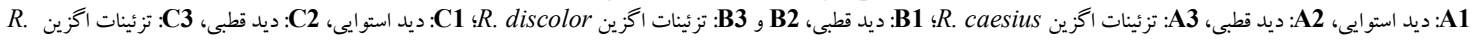
R. hirtus dolichocarpus

A1: equatorial view, A2: polar view, A3: exine-R. caesius; B1: polar view, B2, B3: exine- $R$. discolor; C1: equatorial view, C2: polar view, C3: exine-R.dolichocarpus; D1: equatorial view, D2: polar view, D3: exine- R.hirtus. 


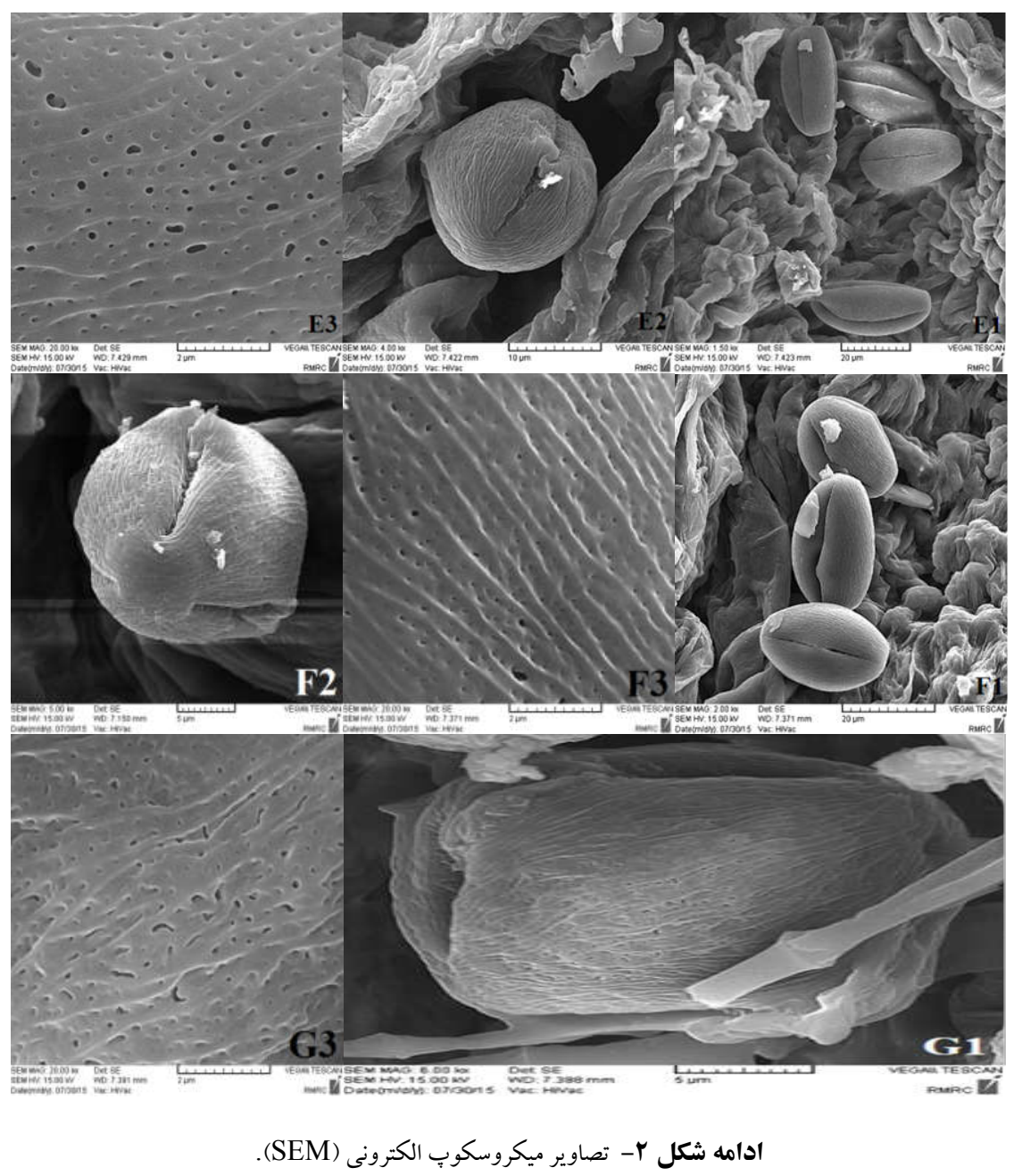

Fig. 2. SEM micrographs.

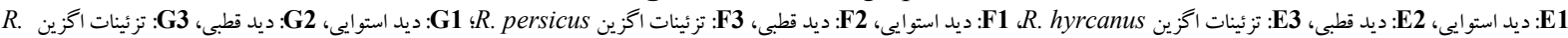

E1: equatorial view, E2: polar view, E3: exine-R. hyrcanus; F1: equatorial view, F2: polar view, F3: exine- $R$. persicus; G1: equatorial view, G2: polar view, G3: exine-R.sanctus.

ميكرومتر و تزئينات شياردار، مطابقت دارد. در مطالعه اخير، گُنهٔ

R. hirtus

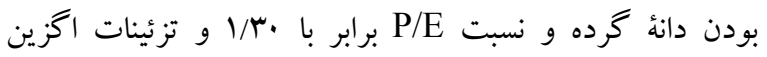

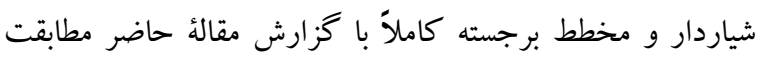

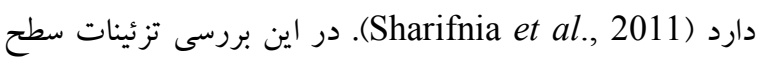
خارجى در گونة R. persicus جرو كيده و R. raddeanus ركهدار يا مخطط معرفى شده است. با توجه به نقش عوامل

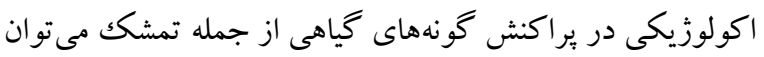

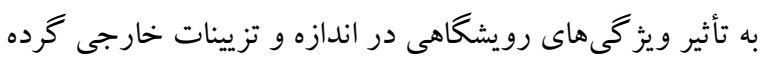

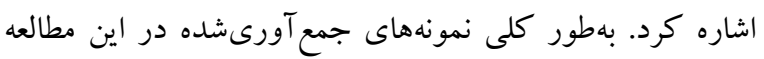

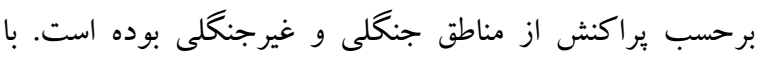

در گردههاى تيره كلسرخيان است (Eide, 1981). سطح تزئينات

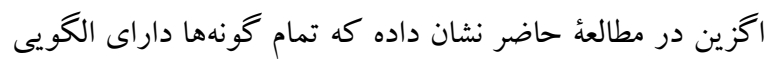

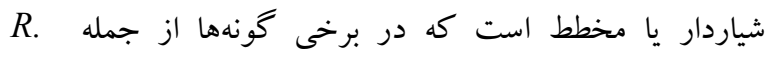
R. sanctus و R. persicus ،hyrcanus مستقيم (striate) و داراى برجستخى كمترى است ولى در ديخر كونها اين شيارها بهصورت برجسته و و جندشاخه (scabrate(striate مطالعات و يافتهاى Tomlik-Wyremblewska (1995) در طرد فرداى مطالعه مورفولوزى گردهء زيرسرده مubus در ارويا، بهجز اندازه كوجك گرده در ديخر گزارشها از جمله بيضوى، سهشياره،

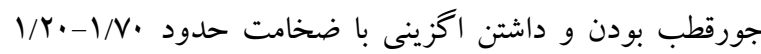




\section{REFERENCES}

Ballington, J.R. Luteyn, M.M., Thompson, K., Romoleroux, K. and Castillo, R. 1993. Rubus and Vacciniaceous germplasm resources in the Andes of Ecuador. - Plant Genet. Resour. Newsl. 93: 9-15.

Boissier, E. 1872. Flora Orientalis 2: 690-694. - H. Georg, Genève.

Davis, P.H. and Meikle, R.D. 1972. Rosacea. - In: Davis, P.H. (ed.): Flora of Turkey and the East Aegean Islands 4: 30-40. - Edinburgh University Press, Edinburgh.

Eide, F. 1981a. Key to the Northwest Rosaceae pollen. Grana 20: 101-118.

Eide, F. 1981b. On the pollen morphology of Rubus chamaemorus (Rosaceae). - Grana 20: 25-27.

Erdthman, G. 1960. The acetolysis method. A revised description. - Svensk. Bot. Tidskr. 54: 561-564.

Erdtman, G. 1943. An introduction to pollen analysis. Chronica Botanical Company Waltham, Mass. 270 pp.

Focke, W.O. 1910. Species Ruborum. Monographiae Generic. Rubi prodromus. - Bibliotheca Botanica 17: 1-120.

Focke, W.O. 1911. Species Ruborum. Monographic Genesis. Rubi prodromus. - Bibliotheca Botanica. 17: 121223.

Focke, W.O. 1914. Species Ruborum. Monographic Genesis. Rubi prodromus. - Bibliotheca Botanica. 17: 1-274.

Ghahreman, A. 1993. Plant systematic cormophtes of Iran. - University Press. 518-568 pp.

Gilli, A. 1969. Rubus. -In: Rechinger, K.H. (ed.): Flora Iranica 66: 67-75 - Akademische Druck-u.-Verlagsanstalt, Graz.

Hummer, K.E. 1996. Rubus diversity. - Hort Science 31: 182-183.

Jennings, D.L. 1988. Raspberries and blackberries: their breeding, diseases, and growth. - Academic Press. New York. $230 \mathrm{pp}$.

Khatamsaz, M. 1992. Flora of Iran (Rosacea). - Research Institute of Forests and Rangelands 6: 20-35.

Mobayen, S. 1996. Rubus. Flora of Iran: Vascular Plants, Vol 4: 167-171. - Tehran University Press, Tehran.

Moore, P.D. and Web, J.A. 1978. An illustrated guide to pollen analysis. - Hodder and Stoughton, London. 30-77 pp.

Parsa, A. 1943. Flore de I'Iran (Flora of Iran) 2: 573-576. Mazaheri Publication, Tehran.

Reitsma, T.J. 1966. Pollen morphology of some European Rosacea. - Acta Bot. Neerl. 15: 290-307.

Richards, A.J., Kirschner, J., Stepanek, J. and Marhold, K. 1996. Apomixis and taxonomy: an introduction. - Folia Geobot. Phytotx. 31: 281-282.

Sharifnia, F. Salimpour, F. and Behzadi Shakib, S. 2011. Revision of Rubus persicus and Rubus raddeanus in Iran. - Quarterly Journal of Plant Sciences Researches 22: 5058.

Thompson, M.M. 1995. Chromosome number of Rubus species at the National Clonal Germplasm Repository. Hort Science 30: 1447-1452.

Thompson, M.M. 1997. Survey of chromosome numbers in Rubus (Rosaceae: Rosoidese). - Ann. Missouri Bot. 84: 128-164.
عنايت به تغييرات عوامل اكولوزيكى از جمله ميزان رطوبت، وزش باد، تغييرات حرارتى و غيره، مىتوان گردهُ تمشك را به دو دسته جنگلى و غيرجنگلى تقسيم نمود در دسته اول مى توان به گونههاى $R$. g R. hyrcanus ،R. dolichocarpus ،R. caesius persicus

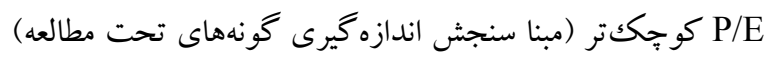
هستند. دسته دوم داراى رويشگاه خارج از جنگل بوده و داراى ويثزىهايى از جمله نسبت P/E بزرگتر نسبت به ديخر گونهها است. تغييرات رويشگاهى بر نوع و تيبّ گرده اثر ندارد و عمدهُ

$$
\text { تغييرات در اندازه كردهها است. }
$$

$$
\begin{aligned}
& \text { سياسگز ارى }
\end{aligned}
$$

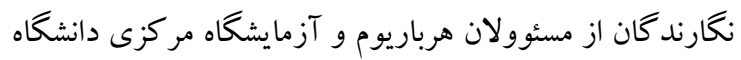

$$
\begin{aligned}
& \text { كنبد كاووس بخاطر فراهم نمودن امكانات و همكارى در انجام اين } \\
& \text { تحقيق قدردانى مىنمايند. }
\end{aligned}
$$


Tomlik-Wyremblewska, A. 1995. Pollen morphology of the genus Rubus L. I. introductory studies on the European representatives of the subgen. Rubus L. - Acta Soc. Bot. 64: 187-203.

Yuzepchuk, S.V. 1941. Rubus L. - In Komarov, V.L. (ed.): Flora of the U.S.S.R 10: 6-45. - Izdatel'stvo Akademii Nauk SSSR, Moskva- Leningrad

\section{$* * * * *$}

\section{How to cite this article:}

Kasalkheh, R., Jorjani, E., Sabouri, H., Habibi, M. and Sattarian, A. 2017. Pollen morphology of the genus Rubus L. subgenus Rubus (Rosaceae) in Iran. - Nova Biol. Rep. 4: 9-18.

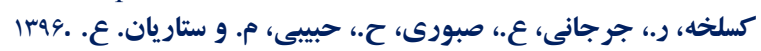

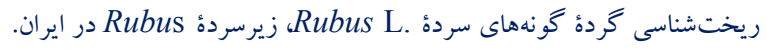

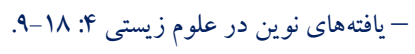

